\title{
Embarazo ectópico sobre cicatriz uterina por cesárea
}

\section{Ectopic pregnancy on uterine scar from cesarean section \\ Gravidez ectópica em cicatriz uterina de cesariana}

\section{Raquel Navas-Campo', Leticia Moreno Caballero², Pilar Tobajas Morlana ${ }^{3}$}

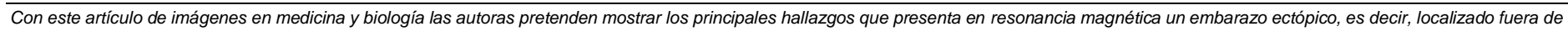

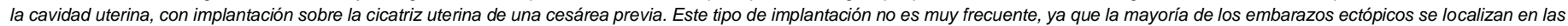
trompas, por lo que es de vital importancia su diagnóstico precoz para permitir realizar un tratamiento que evite la aparición de complicaciones graves e intente preservar la fertilidad. .

\section{Resumen:}

1- Residente de $4^{\circ}$ año de la especialidad de radiodiagnóstico en el el Hospital Clínico Universitario Lozano Blesa. Zaragoza, España. Master en iniciación a la investigación en medicina. E-mail de contacto: raquelnavascampo@gmail.com

2- Residente de 4ํaño del Hospital Clínico Universitario Lozano Blesa. Zaragoza, España. Master en iniciación a la investigación en medicina.

3- Médico especialista en raidodiagnóstico del Hospital Clínico Universitario Lozano Blesa. Zaragoza, España. Doctora en medicina.

Recibido: 2021-03-09 Aceptado: 2021-11-27

DOI: http://dx.doi.org/10.31053/1853.0605.v78.n4.32407

cc) (i) (8)

(C) Universidad Nacional de Córdoba
El embarazo ectópico se define como la implantación del óvulo fecundado fuera de la cavidad uterina. Alrededor del $95 \%$ de los embarazos ectópicos se localizan en la trompa. Las formas no tubáricas, en concreto sobre la cicatriz de una cesárea, son una entidad muy poco frecuente cuyo diagnóstico y tratamiento precoz son imprescindibles para evitar complicaciones graves y preservar la fertilidad.

Palabras claves: embarazo ectópico; cesárea; imagen por resonancia magnética; ultrasonografía.

Abstract:

Ectopic pregnancy is defined as the implantation of the fertilized egg outside the uterine cavity. About $95 \%$ of ectopic pregnancies are located in the tube. Non-tubal forms, in particular on the scar of a cesarean section, are a very rare entity whose early diagnosis and treatment are essential to avoid serious complications and preserve fertility.

Keywords: pregnancy, ectopic; cesarean section; magnetic resonance imaging; ultrasonography.

\section{Resumo}

A gravidez ectópica é definida como a implantação do óvulo fertilizado fora da cavidade uterina. Cerca de $95 \%$ das gravidezes ectópicas estão localizadas no tubo. As formas não tubulares, especificamente na cicatriz de uma cesariana, são uma entidade muito rara cujo diagnóstico e tratamento precoce são essenciais para evitar complicações graves e preservar a fertilidade.

Palavras-chave: gravidez ectópica; cesárea; imagen por ressonância magnética; ultrassonografia. 
CASO E IMÁGENES

El embarazo ectópico se define como la implantación del óvulo fecundado fuera de la cavidad uterina. Es la primera causa de morbilidad y mortalidad materna en el primer trimestre de la gestación. Alrededor del $95 \%$ de los embarazos ectópicos se localizan en la trompa. Las formas no tubáricas son menos frecuentes.

El embarazo ectópico en cicatriz de cesárea previa es una forma muy poco frecuente y potencialmente mortal de implantación anormal de un saco gestacional dentro del miometrio y el tejido fibroso de la cicatriz. ${ }^{1}$ La prevalencia oscila entre 1:1800 y 1:2226 embarazos, y corresponde solo al $6,1 \%$ de los embarazos ectópicos en mujeres con una cesárea previa ${ }^{2}$.

Se han descrito dos tipos, uno que crece hacia la cavidad uterina (pudiendo llegar a término) y el otro que crece hacia el exterior uterino, pudiendo dar lugar a una rotura uterina o a la invasión de otras estructuras pélvicas. ${ }^{3}$

Su diagnóstico y tratamiento precoz puede prevenir complicaciones como hemorragia, rotura uterina y puede preservar la fertilidad.

Femenino 39 años, embarazada de $14+4$ semanas con antecedentes de 2 cesáreas previas. Acude a la consulta de ginecología para la revisión del $1^{\circ}$ trimestre de embarazo. En la ecografía se identifica feto único en presentación cefálica con latido cardiaco presente (Figura 1), objetivando una implantación ectópica sobre la cara anterior del útero, en la región de la cicatriz de cesárea previa. Se presenta el caso en sesión clínica y se decide ampliar el estudio mediante resonancia magnética.

Se realiza RM con secuencias potenciadas en T2 en plano sagital (figura 2), coronal (figura 3.A) y axial (figura 3.B). Se objetiva saco gestacional de unos $9,5 \mathrm{~cm}$. implantado en la cara anterior del cuerpo uterino, con feto de $14+6$ semanas en su interior (flecha negra fina) y placenta de localización anterior (punta de flecha negra). Está únicamente cubierto por la serosa uterina en su porción anterior (flecha negra gruesa). Desplaza posteriormente la pared anterior del cérvix uterino (flecha blanca fina) y comprime sin infiltrar la pared superior de la vejiga (punta de flecha blanca), desplazándola caudalmente. Se aprecia endometrio de características normales no gravídicas (flecha blanca gruesa) y cicatriz de cesáreas previas en tejido celular subcutáneo (estrella blanca).

Se realizó exéresis del embarazo ectópico por laparotomía con reconstrucción de pared miometrial, previa cateterización de uréteres, sin incidencias.

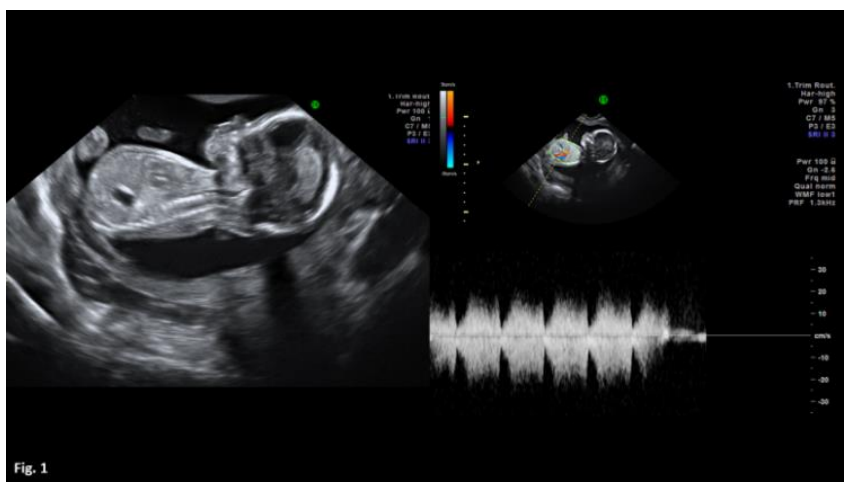

Figura 1: feto único en presentación cefálica con latido cardiaco presente.

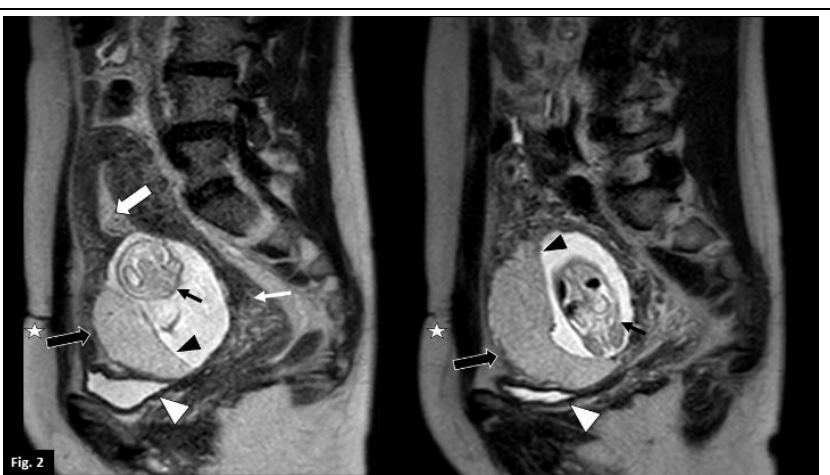

Figura 2: RM con secuencias potenciadas en T2 en plano sagital.

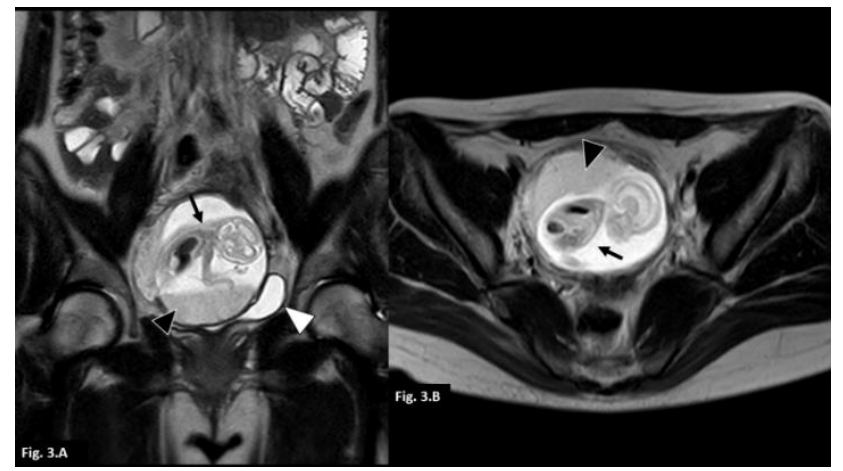

Figura 3.A y 3.B: RM con secuencias potenciadas en T2 en coronal y axial.

Limitaciones de responsabilidad

La responsabilidad del trabajo es sólo de los autores

Conflictos de interés

Ninguno

Fuentes de apoyo

No posee.

Originalidad del trabajo

Este artículo es original y no ha sido enviado para su publicación a otro medio de difusión científica en forma completa ni parcialmente.

\section{Cesión de derechos}

Los participantes de este trabajo ceden el derecho de autor a la Universidad Nacional de Córdoba para publicar en la Revista de la Facultad de Ciencias Médicas y realizar las traducciones necesarias al idioma inglés.

Participación de los autores

Todos los autores hemos participado en la concepción del diseño, recolección de la información y elaboración del manuscrito, haciéndose públicamente responsables de su contenido y aprobando su versión final.

\section{Bibliografía}

1. Shen L, Tan A, Zhu H, Guo C, Liu D, Huang W. Bilateral uterine artery chemoembolization with methotrexate for cesarean scar pregnancy. Am J Obstet Gynecol. 2012 Nov;207(5):386.e1-6. doi: 10.1016/j.ajog.2012.09.012.

2. Patel MA. Scar Ectopic Pregnancy. J Obstet Gynaecol India. 2015 Dec;65(6):372-5. doi: 10.1007/s13224-015-0817-3.

3. Vial $Y$, Petignat $P$, Hohlfeld $P$. Pregnancy in a cesarean scar. Ultrasound Obstet Gynecol. 2000 Nov;16(6):592-3. doi: 10.1046/j.1469-0705.2000.00300-2.x. 